\title{
DANTE ALIGHIERI PROFETA DA ONU?
}

\author{
IUIGI CASTAGNOLA \\ Universidade Federal do Paraná
}

José Nicolau dos Santos, no seu livro "ONU - Estado, Proto-Estado ou Super-Estado?"(1) - rico de erudição histórica, jurídica e filosófica, menciona em primeiro lugar Dante Alighieri, filósofo e poeta, entre os que, no passado, sustentaram (De Monarchia) a necessidade da criação de um império universal. "Pelas tendências históricas diz ainda o mencionado jurista, hoje catedrático da Universidade Federal do Paraná - verificamos que as soluções alvitradas no passado não diferem das que continuam discutidas no presente"(2).

O jurista paranaense não é, por certo, uma voz isolada quand's vê correspondências, não igualdades de soluções, entre a Monarquia Universal de Dante Alighieri e a Organização das Nações Unidas. Na revista "Vita Italiana - Documenti e Informazioni", de janeiro de 1966, encontramos um artigo, cujo título é "Dante e l'ONU"(3). O autor do artigo foi levado a fazer algumas observações suggeridas pelas ressonâncias mundiais que tiveram as celebrações do sétimo centenário do nascimento do poeta e filósofo florentino. Útil para as finalidades de nosso trabalho é a transcrição de um trecho do mencionado artigo.

"Uno studio comparato tra la dottrina politica di Dante e gli organi internazionali, intercontinentali e mondiali, sorti nel secondo dopo-guerra, porterebbe, anche se pienamente valido, ad un ampliamento poco utile ai fini di questa trattazione. Prendiamo a partito il maggior or-

1. José Nicolau DOS SANTOS, ONU - Estado, Proto-Estado ou Super-Estador, Curitiba, 1952, pág. 189.

2. José Nicolau DOS SANTOS, ob. cit., pág. 188.

3. Vita Italiana - Documenti - Informaxioni, Roma, 1966, fasc. 1, pp. 65.72. 
ganismo mondiale, I'ONU, comprese le sue due grandi agenzie: Unesco, Fao, allo scopo di raffronto con il Monarcato Universale. Si delinea innanzi tutto una profonda differenza: I'ONU è una realtà operante; il Monarcats una costruzione ideale, soltanto pensata. Ma anche l'ONU, prima di diventare una realtà, è sta:a meditata e pensata. I due documenti in sé sono dunque del tutto comparabili, nonostante siano distanziati da sette secoli.

In base a quanto Dante ha scritto sulle fur.zioni naturali di un potente organo rondiale per la giustizia, II diritto, la pace, la libertà, l'unità e la solidarietà umana, è visibile nella massima associazione mondiale vivente ed operante ai nostri giorni, un'incarnazione della umana c:viltà dantesca.

Nello Statuto approvato a Sar. Francisco il 26 giugno 1943, gli scopi dell'ONU vennero cosi delimitati:

a) Salvare le future generaziori dal flagello della guerra

b) Riaffermare la fede nei diriti fondamentali dell'uomo

c) Creare le condizioni per risolvere, con il diritto e la giustizia, le controversie tra i popoli

d) Promuovere il progresso sociāle ed un più elevato tenore di vita in una più ampia libertà.

I quattro imperativi sono del tutto simili - a parte :a forma e le parole - alle meditazioni dell'Alighieri. Del pari aderente alla dottrina dantesca è l'altro documento che va sotto il nome di "Dichiarazione Universale dei Diritti dell'Uomo", aprovato dall'Assemblea Generale delI'ONU il 10 dicembro 1948. Si afferma nel preambolo di riconoscere "a tutti i membri della famiglia umana dirifti uguali ed inalienabili quale fondamento delia libertà, della pace e deila giustizia nel miondo". Si ammette poi che: "la inosservanza dei diritti ha costituito la causa principale di tutti i mali e degli atti di barbarie che, anche recentemente, hanno mortificato ed offeso tante volte la coscienza dell'umanita".

L'ONU e Dante, pure in ambienti e tempi profondamenie diversi, vedono alio stesso mudo gli stessi proble. mi. Anche il metodo di esposizione è identico in modo sorprendente: como nella Dichiarazione dei Diritti del- 
I'uomo, Dante prima costruisce il suo Monarcato - secondo la natura degli vomini e i loro sentimenti - quindi mostra gli effetti del comportamento obliquo, che turba la concordia, la vita operosa, la pace. La stessa definizione del diritto (proporzione che osservata conserva la società, corrotta la corrompe) trova corrispondenza nella Dichiarazione (la inosservanza del diritto è la causa dei mali. . che hanno offeso la coscienza dell'umanità).

Chi abbia presente il quadro della teoria di Dante, i due documenti citati e l'attività dell'ONU nella sua funzione unitaria e universale, sarà indotto a scorgere nel pensiero dantesco una portentosa profezia, collaudata dal. la mirabile realtà dell'ONU'(4).

Foi realmente grande a importância de Dante Alighieri no mundo político de seu tempo? A resposta pode ser afirmativa, sem dú vida. Mas é preciso, preliminarmente, fazer uma distinção entre Dante homem público e político militante e Dante tratadista, autor de doutrinas políticas. Mesmo como homem político, Alighieri desempenhou funções importantes no govêrno de Florença e na política italiana de seu tempo; não tivesse escrito, porém, a Divina Commedia e as demais obras, ficaria uma figura secundária entre os políticos de sua época. Como tratadista e autor de filosofia política, pelo contrário, Dante avulta não sòmente entre os homens de seu tempo, mas deixou também uma mensagem que, conforme salientava já Francisco De Sanctis no século findo, marcava o caminho da história.

Dante Alighieri dedicou à política florentina sete anos. Sua atuação começou em 1295 e terminou em 1302, quando foi injustamente condenado e desterrado para sempre de sua pátria.

Sendo nobre, teve que ingressar na corporação dos médicos $ə$ farmacêuticos, não permitindo a lei que os nobres entrassem na vida pública sem antes pertencer a uma corporação. De novembro de 1295 até abril de 1296, fêz parte do Conselho Especial do Povo. Em dezembro de 1295 entrou no Conselho dos Sábios, que devia eleger os Priores de Florença. Em 1296 foi eleito membro do Conselho dos Cem. Certamente se distinguiu entre seus colegas, porque, em 1300, foi enviado embaixador a San Gemignano, e, no mesmo ano, foi eleito prior de Florença, o cargo político mais importante da cidade. No Priorado, que Dante exerceu juntamente com outros dois colegas, desde 15 de junho até 15 de agôsto de 1300, o poeta defendeu, com moderação e firmeza ao mesmo tempo, a liberdade de Florença con-

4. Ob. cit., pp. $70-71$. 
tra as ambições políticas de Bonifácio VIII; demonstrou também sua imparcialidade e isenção quando teve que assinar a condenação ao exílio do amigo e poeta furbolento Guido Cavalcanti. Depois de ter dei xado o cargo de prior, conforme a lei mandava, continuou exercendo intensa atividade política, a partir de abril de 1301, tendo sido eleito membro de um Conselho das Artes. Em junho do mesmo ano faz parte do Conselho dos Cem; em setembro toma parte nas reuniões do Conselho dos Cem, do Conselho do Capitão do Povo, e das Artes; ainda participa dos Conselhos reunidos dos Cem, do Capitão e das Artes. Em outubro, juntamente com Corazza da Signa e Maso Minerbetti, foi finalmente enviado embaixador ao papa Bonifácio VIII a fim de conseguir a benevolência do famoso pontífice em relação a Florença.

Entrementes, Carlos de Valois, irmão do rei da França e capitão geral da Igreja, incumbido por Bonifácio VIII de pôr ordem na Toscana, entra em Florença e entrega o poder ao partido dos Neri. O nôvo govêrno, tendo à frente Cante de' Gabrielli d'Agubbio, começa uma série de perseguições e processos contra os antigos adversários políticos. Em janeiro de 1302 também Dante, que estava ainda em Roma, é condenado por ter realizado "per se vel per alium barattarias, lucra illicita, iniquas extorsiones in pecunia vel in rebus". O desafortunado poeta foi condenado a fazer restituição das coisas extorquidas, a pagar a multa de 5.000 florins, a ficar por dois anos fora da Toscana, e à perda dos direitos civis para sempre. Dante compreendeu que as paixões políticas desencadeadas não lhe permitiriam uma defesa serena e não se apresentou aos trịbunais de Florença. Foi então atingido por nova sentença condenatória que o bania para sempre da pátria, e o condenava a ser queimado vivo se fôsse prêso no território da república.

Findava, assim, sua atuação no campo da política militante, e começava seu exílio, que devia durar até a morte (1321).

Dante pertencia, porém, à categoria dos homens cujo espírito é animado pela chama do gênio. Se as circunstâncias históricas e as injustiças humanas o afastavam tão dramàticamerite da política, não conseguiriam, no entanto, apagar o sôpro da atividade que o impul sionava. No exílio não sòmente desenvolveu uma atividade literária intensa, cujo fruto mais precioso foi a Divina Commedia, a obra-prima da poesia italiana, mas continuou meditando sôbre o problema político, sempre tão premente para o indivíduo e para a humanidade. Concretizava assim suas meditaçōes de filosofia política no tratado De Monarchia, cujo ano de composição não é possível precisar. E opinião corrente entre os estudiosos de Dante que a obra tenha sido es 
crita entre 1312 e 1313, quando o imperador Arrigo VII foi à Itália, há outrossim quem pensa numa época um pouco posterior(5), pelo menos para a redação definitiva da obra, visto que os anos agitados da descida de Arrigo VII à Itália não haveriam proporcionado ao poeta a tranqüilidade e o tempo necessários para a composição de um tratado tão bem estruturado e amadurecido como o De Monarchia.

Dante viu a dificuldade prática da realização de sua monarquia universal, por causa dos interêsses e das paixões dos que deveriam levar a humanidade à sua felicidade eterna e temporal; mas nem por isso foi abalado seu ideal político. Haverá de chegar o dia em que a sociedade humana será governada por um só monarca, que cuide da felicidade terrestre dos homens, e por um pontífice, que cuide da felicidade eterna de todos os indivíduos. "Na ordem da civilização comum, a tendência de todos os povos cristãos para uma superior unidade orgânica e espiritual da cidade terrena, Dante sentiu-a tão enraigada nos corações que a almejou idealmente além e apesar das circunstâncias contrárias, meditando sôbre um mundo unificado temporalmente por um monarca, assim como estava espiritualmente unificado pelo papa na lgreja de Cristo"(6).

No De Monarchia, Dante quer indagar o seguinte: se a Monarquia temporal, ou Império, ou govêrno de um só, é necessária para o bemestar do mundo; se o povo romano se atribuiu a si mesmo legìtimamente o ofício da Monarquia ou Império; se a autoridade do monarca depende imediatamente de Deus ou então de um ministro ou vigário de Deus. A cada uma destas questões Dante dedicou um livro de seu tratado.

Numa breve introdução, Dante reconhece que o seu empreendi. mento é árduo e até superior às suas fôrças, mas nem por isso quer deixar de prestar um serviço à República, revelando algumas verdades desconhecidas sôbre a filosofia política, a fim de que ninguém o acuse mais tarde de ter enterrado seu talento, e também "para que a palma de ter sido o primeiro na emprêsa se acrescente à minha glória"(7).

O poeta filósofo esclarece logo o que êle entende por Monarquia temporal: "A Monarquia temporal, chamada Império, é o Principado único, superior a todos os demais poderes no tempo, e aos sêres e coisas que pelo tempo se medem"(8).

5. Cf. Piero BARGELLINI, Vita di Danto, Florença, 1964, p. 194.

6. Mario CASELLA, Introduzione alle opere di Dante, Miláo, 1965, pp. 53-54.

7. De Monarchis, I. 1. Citamos a tradução do Dr. João Penteado E. Stevenson, Sāo Paulo, 1960.

8. De Monarchia, I, 2. 
A ação política depende de nós, afirma Alighieri, diversamente "das coisas matemáticas, físicas e divinas"(9), que o homem pode especular mas não realizar. O Principado único pode, então, ser realizado pelo homem; e deve ser realizado por êle, porque diversamente não alcançará seu fim principal, sua perfeição. Como há um fim para tôda sociedade humana particular, bem como para o indivíduo, deve haver também uma finalidade para o gênero humano; é uma "estultície acreditar-se que existe um fim para esta ou aquela sociedade e que não há um fim único para todos"(10). O fim último, isto é, a perfeição suprema da humanidade é a fôrça ou virtude intelectiva, pela qual será realizada a felicidade terrestre do gênero humano. $E$, no entanto, uma ilusão pensar que se possa alcançar essa finalidade, sem a paz e a liberdade; por conseguinte, a ação política deve proporcionar ao gênero humano a paz universal, sendo esta o melhor de todos os meios ordenados à nossa felicidade. Os povos da terra, que têm uma finalidade suprema e comum, como foi demonstrado, não a poderão alcançar sem que haja um único e supremo governador que dirija a todos, porque "todo reino dividido será desolado" segundo afirma a verdade inefável(11).

Sem a Monarquia universal, ou Império ou Principado único, o gênero humano e nem os povos particulares serão livres, porque todo povo mais forte poderá oprimir os povos mais fracos, os quais nem sequer poderão existir se o povo mais forte, sendo mau, pretender injustamente subjugá-los. O Monarca universal não tem apetites ou paixões, porque não tem nada que desejar, "pois sua jurisdição termina no Oceano, o que não ocorre com os outros príncipes, cujos principados terminam onde começam outros"(12). E visto que os cônsules existem para os cidadãos e não os cidadãos para os cônsules, nem o povo existe para o Rei, mas o Rei para o povo, assim o Monarca universal, embora pelos meios seja senhor dos demais, em razão do fim deve ser considerado, sem dúvida, o servidor de todos(13).

Argumentando por diversos modos, Dante chega sempre à conclusão de que, para a felicidade do gênero humano, é necessária a Monarquia universal.

Monarca universal, entretanto, deverá governar os diversos reinos e nações com leis diferentes, sendo a lei uma regra diretiva da vida. E não teria sentido governar os habitantes das regiões polares, onde impera um frio quase intolerável, como os que povoam as

9. Do Monarchia, 1, 3.

10. De Monarchia, 1, 3.

11. Cf. De Monarchia, 1, 7.

12. De Monarchia, 1, 13.

13. Cf. De Monarchia, I, 14. 
regiōes equatoriais, os quais "têm sempre a luz igual à noite e não suportam vestimentas no ardor do estio"(14).

No segundo livro do De Monarchia Dante sustenta que o povo romano obteve legitimamente o ofício da monarquia ou império. As argumentações aduzidas para demonstrar a tese são quase totalmente desprovidas de validade histórico-filosófica, e até poderão parecer um tanto pueris a um leitor da atualidade. Mas não se deve esquecer - para se entender o núcleo essencial do pensamento dantesco sôbre êste assunto - que Alighieri viveu, pensou e escreveu numa época em que a visão histórica, geográfica e cultural da humanidade era bem diversa da atual. O mundo civilizado do tempo de Dante estava ainda sob a fascinação da grandeza militar, política e cultural do império romano, e ainda não haviam aparecido as grandes nações da época moderna, e os grandes povos da atualidade estavam no estado potencial. Em nossos dias, quando o mundo está sob a fascinação do poderio político, militar e cultural de outros impérios, não há porventura quem ambicione - e não só platônicamente - a monarquia universal, ou almeje o prevalecer dêste ou daquele império da atualidade, ou pense no domínio universal dêste ou daquele povo? Pois bem, pensam êles em nossa época exatamente como pensava Dante Alighieri na sua, com uma diferença fundamental porém: Dante desejava a realização da sua Monarquia universal pelos caminhos do direito, da justiça e da liberdade, o que não se pode certamente afirmar de todos os impérios modernos que acalentam sonhos de monarquia universal.

Mas a parte do tratado que devia ter mais ressonância no momento histórico em que viveu Dante, é a terceira, em que o famoso florentino sustenta depender imediatamente de Deus a autoridade da Monarquia.

"A questão que nos cumpre examinar se esbate agora entre dois grandes luminares: a saber, o Pontífice Romano e o Príncipe Romano; consiste em estabelecer se a autoridade do Monarca dos Romanos, que é legítimo Monarca do mundo, como se provou no Segundo Li. vro, depende imediatamente de Deus ou de algum vigário ou minis. tro de Deus; com o que consigno o sucessor de Pedro, que realmente é o chaveiro do reino celeste"(15). Através de uma longa série de argumentações e polêmicas de caráter histórico, jurídico, filosófico e escriturístico, que a crítica não acha sempre válidas e até acusa, por vêzes, de ilógicas, Dante conclui desta forma: "Digo, pois, que o reino temporal não recebe o ser do espiritual, nem suas faculdades,

14. De Monarchia, 1, 16.

15. De Monarchia, III, I. 
que são a sua autoridade, nem tão pouco pura e simplesmente sua operação; recebe, porém, sim, para agir melhor e mais eficazmente, a luz da graça, que no céu e na terra lhe infunde a bênção do Sumo Pontífice"(16).

Não é possível, num trabalho desta natureza, analisar em seus complicados aspectos jurídicos, políticos, históricos e religiosos a famosa controvérsia medieval entre o Guelfismo absoluto - que queria a subordinação total dos monarcas e do imperador ao papa - e o Gibelinismo absoluto, que sustentava, pelo contrário, a subordinação dos bispos e do papa ao imperador. Dante, passando por cima das teorias guelfa e gibelina, afirma que os homens têm direito a duas vidas e duas felicidades: a terrena e a celeste. Há, portanto, dois fins máximos do homem: a felicidade temporal neste mundo, e a bem-aventurança espiritual no céu. Com base nesta distinção fundamental, Alighieri afirma a necessidade de duas autoridades supremas e independentes uma da outra: a do papa e a do monarca ou imperador. $O$ primeiro detém o poder espiritual e deve guiar os homens à felicida. de eterna; o segundo detém o poder temporal, e deve levar o gênero humano ao bem-estar terreno. Tanto o papa como o monarca recebem diretamente de Deus sua autoridade.

Dante era, porém, sinceramente cristão, e compreendia e declarava que a vida e a felicidade terrena estavam ordenadas à vida e à felicidade celeste. Por isso, terminava o De Monarchia com estas palavras: "Cumpre anotar que a verdade relativa a esta última questão (isto é, que o Monarca depende diretamente de Deus e não de um ministro de Deus) não se deve admitir de tal forma estritamente que faça com que o Príncipe romano não se quede em nada submetido ao Romano Pontífice; a felicidade mortal está de certa maneira condi cionada à felicidade imortal. Cumpre a César empregar, no que respeita a Pedro, a mesma reverência que o filho primogênito deve dis. pensar a seu pai, para que, iluminado pela graça paternal, irradie com maior virtude sôbre o orbe terrestre, que the foi outorgado por Aquêle - o único governador de tôdas as coisas espirituais e temporais " (17).

O De Monarchia despertou acirradas polêmicas, antigas e modernas; muitas delas são devidas à contingência histórica das argumentações dantescas, outras à falta de preparo cultural dos leitores para a justa compreensão do pensamento político de Dante e do conteúdo histórico e teorético do discutido tratado.

O ideal político de Dante foi por alguns considerado utópico e

16. Do Monarehia, III, 4.

17. De Monarchia, III, 16. 
ilógicas e frágeis algumas suas argumentações. Um crítico literário da envergadura de Francisco De Sanctis - que foi, também, uma das figuras políticas importantes do Ressurgimento liberal italiano do século findo - afirmou, no entanto, que as idéias mestras do De Monarchia marcavam o caminho da história.

Com efeito, as tendências históricas dos séculos que se seguiram a Dante Alighieri vieram demonstrar que o núcleo essencial das doutrinas políticas do filósofo e poeta florentino coincide com os anseios da evolução política da humanidade.

Dante, a par dos grandes intelectos, viu o problema político sob - prisma da universalidade. As lutas contínuas e seculares entre o gibelinismo e o guelfismo extremados pareciam-lhe estéreis, infecundas e prejudiciais à felicidade do gênero humano. Espírito pacifista, desagradavam-lhe as intrigas políticas e as rixas intermináveis entre os pequenos ou grandes príncipes de sua época, causadoras de sofrimentos para os povos e entraves para o progresso da humanidade. Por outro lado, a evolução histórica fêz desaparecer os inúmeros e briguentos países em que estava dividida a Itália da época de Dante; as nações modernas, não poucas vêzes, tentaram de se tornarem monarquias ou impérios universais, recorrendo à fôrça bruta, e não ao direito e à justiça como almejava Dante. Em nossos dias as tentativas, teóricas ou práticas, de uniões pan-européia, pan-americana, pan-africana, pan-asiática parecem confirmar os anseios modernos tendentes a uma monarquia ou govêrno universal. A Liga das Nações e a Organização das Nações Unidas poderiam ser consideradas instituições jurídicas e políticas criadas pela mentalidade moderna, não muito diferentes, no fundo, da monarquia universal dantesca, para alcançar as mesmas finalidades. Ainda recentemente foi escrito:

"Parrebbe lecito riconoscere in Dante politico maggiore aderenza alle superiori, ma reali esigenze della società umana, di quel che non si sia giudicato finora. Se è vero, infatti, che, rispetto alla realtà stcrica dei suoi tempi, Dante sostenitore della Monarchia universale appare un illuso o un sognatore, non si potretbe dire fuori della realtà possibile la sua teoria della necessità di un'autorità politica universale, superiore alle singole autorità, che, pur rispettando gl'interessi particolari dei singoli Stati, imponga leggi a tutti per ciò che riguarda gl'interessi ger.erali di tutta l'umanità e la pace del mondo"(18).

O tratado de Dante sôbre as relações entre o poder temporal e

18. Siro A. CHIMENZ, Dante, in Letteratura Italiana - I Maggiori, Milão, 1956, I. I, p. 45. 
- poder espiritual, nalguns pontos, pode parecer perigoso; nem foi sem motivo que o Cardeal Bertrando del Poggetto, em 1329, mandou queimar em praça pública os três livros do De Monarchia. Mas a solução que Dante deu a êste espinhoso problema político

"è la base su cui si sono fondati i rapporti tra Chiesa e Stato nella storia moderna. Si tratta, certo, di una solu zione di equilibrio e di compromesso, che, non avendo una base rigorosamente logica, la storia insegna quanto sia stata e sia instabile; ma è una soluzione, malgrado questo, praticamente viva e operante; il che dimostra che, se Dante loico è in difetto, il politico aveva avuto intuito felice"(19).

E doutrina hoje ensinada oficialmente nas faculdades católicas de direito que "Ecclesiae non competit potestas directa in res temporales"(20), e que a "autoridade temporal tem sua origem diretamente de Deus, autor da natureza"(21).

O pensamento político de Dante Alighieri é, portanto, fecundo. Suas teorias sôbre o govêrno da humanidade, em seu núcleo essencial e profundo, parecem receber confirmação pela evolução do fenômeno político. "Sem dúvida, o De Monarchia é, formalmente, uma obra tìpicamente medieval e abstrata; mas, sob aquela abstrata especulação medieval, há uma consciência apaixonada, em que se encontram vivos e concretos, como na consciência moderna, os problemas fundamentais da humana civiliłas: paz, progresso, liberdade"(22).

19. Idem, ibidem, p. 45.

20. Alaphridus OTTAVIANI, Compendium luris Publici Ecelesiastici, Roma, 1936, p. 357.

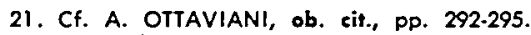

22. Siro A. CHIMENZ, ob. cit., p. 45. 